\title{
In elective arch surgery with circulatory arrest, does the arterial cannulation site really matter? A propensity score analysis of right axillary and innominate artery cannulation

\author{
Ourania Preventza, MD, ${ }^{\mathrm{a}, \mathrm{b}}$ Matt D. Price, MS, ${ }^{\mathrm{a}}$ Konstantinos Spiliotopoulos, MD, PhD, \\ Hiruni S. Amarasekara, MS, ${ }^{\mathrm{a}, \mathrm{b}}$ Lorraine D. Cornwell, MD, ${ }^{\mathrm{a}, \mathrm{c}}$ Shuab Omer, MD, ${ }^{\mathrm{a}, \mathrm{c}}$ \\ Kim I. de la Cruz, MD, ${ }^{\mathrm{a}, \mathrm{b}}$ Qianzi Zhang, MPH, ${ }^{\mathrm{a}}$ Susan Y. Green, MPH, ${ }^{\mathrm{a}, \mathrm{b}}$ \\ Scott A. LeMaire, MD, ${ }^{\mathrm{a}, \mathrm{b}}$ Todd K. Rosengart, MD, ${ }^{\mathrm{a}, \mathrm{b}}$ and Joseph S. Coselli, MD ${ }^{\mathrm{a}, \mathrm{b}}$
}

\section{ABSTRACT}

Objective: The preferred arterial cannulation site for elective proximal aortic procedures requiring circulatory arrest varies, and different sites have been tried. We evaluated the relationships between arterial cannulation site and adverse outcomes, including stroke, in patients undergoing elective aortic arch surgery.

Methods: We reviewed the records of 938 patients who underwent elective hemiarch or total arch surgery with circulatory arrest between 2006 and 2016. Five cannulation sites were used: the right axillary $(\mathrm{n}=515 ; 54.9 \%)$, innominate $(\mathrm{n}=376 ; 40.1 \%)$, and right common carotid arteries $(\mathrm{n}=15 ; 1.6 \%)$, each with a side graft; the ascending aorta $(\mathrm{n}=19 ; 2.0 \%)$; and the femoral artery $(\mathrm{n}=13 ; 1.4 \%)$. Multivariable logistic regression analysis was used to model the effects of cannulation site on adverse outcomes for the entire cohort and for a subcohort of 891 patients who underwent innominate or axillary artery cannulation. Propensity-matching yielded 564 patients (282 pairs) from the right axillary and innominate artery groups.

Results: For the entire cohort, mortality, stroke, and composite adverse outcome (operative death or persistent stroke or renal failure at hospital discharge) rates were $7.0 \%, 4.1 \%$, and $9.8 \%$. In the multivariable analysis of the axillary/ innominate subcohort, cannulation site did not independently predict operative mortality, persistent stroke, or composite adverse event. These results were confirmed with the propensity-matched analysis, where both axillary and innominate artery cannulation provided equivalent composite adverse event rates, operative death rates, and overall stroke rates.

Conclusions: During elective arch surgery, right axillary artery cannulation and innominate artery cannulation (both via a side graft) produce excellent results and can be used interchangeably. (J Thorac Cardiovasc Surg 2018;155:1953-60)

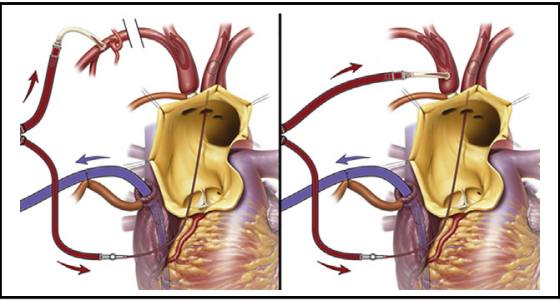

Axillary (left) and innominate (right) inflow cannulation for cardiopulmonary bypass.

Central Message

Axillary artery cannulation and innominate artery cannulation (both via a side graft) provide excellent results and can be used interchangeably.

Perspective

In the modern era, with modern imaging modalities, the cannulation site should be chosen in a way that facilitates the operation and minimizes complications. Different cannulation strategies can be used to establish arterial inflow for elective proximal and total arch cases. Innominate and axillary artery cannulation with a side graft provide equivalent results, with no clear winner.

See Editorial Commentary page 1961.
Various cannulation techniques have been used for proximal thoracic aortic surgery, although which cannulation site is best remains controversial among cardiothoracic surgeons. ${ }^{1-4}$ Neuroprotection strategies target

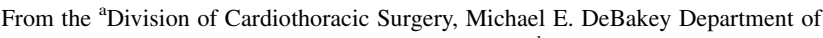
Surgery, Baylor College of Medicine, Houston, Tex; ${ }^{b}$ Department of Cardiovascular Surgery, Texas Heart Institute, Houston, Tex; and ${ }^{\mathrm{c}}$ Division of Cardiothoracic Surgery, Michael E. DeBakey Veterans Affairs Medical Center, Houston, Tex. Received for publication May 18, 2017; revisions received Nov 14, 2017; accepted for publication Nov 26, 2017; available ahead of print Jan 17, 2018.

Address for reprints: Ourania Preventza, MD, Division of Cardiovascular Surgery, Texas Heart Institute, One Baylor Plaza, Houston, TX 77030 (E-mail: opsmile01@aol.com).

$0022-5223 / \$ 36.00$

Copyright (c) 2017 by The American Association for Thoracic Surgery https://doi.org/10.1016/j.jtcvs.2017.11.095
}

minimizing circulatory arrest time and reducing cerebral metabolic demand with various levels of hypothermia. The equivocal evidence supporting the use of different cannulation strategies during elective proximal and total arch surgery suggests that "there is more than one way to skin a cat." Various strategies, including direct or indirect (ie, via a side graft) cannulation of the right axillary,

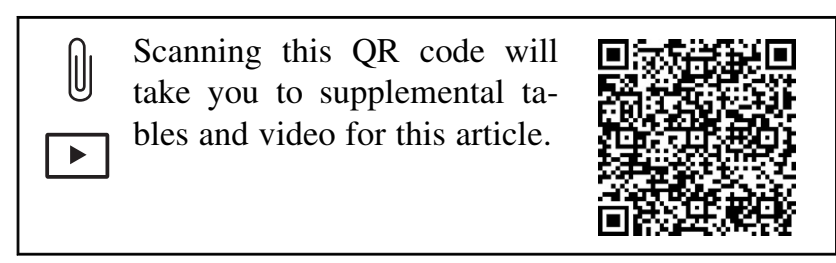




\section{Abbreviations and Acronyms}

$\mathrm{ACP}=$ antegrade cerebral perfusion

$\mathrm{CI}=$ confidence interval

$\mathrm{CPB}=$ cardiopulmonary bypass

$\mathrm{DHCA}=$ deep hypothermic circulatory arrest

$\mathrm{OR}=$ odds ratio

$\mathrm{SE} \quad=$ standard error

innominate, or right common carotid artery, can be used to provide antegrade cerebral perfusion (ACP) during circulatory arrest, thereby making straight deep hypothermic circulatory arrest (DHCA) unnecessary. Direct aortic cannulation under echocardiographic guidance is becoming increasingly popular. Femoral artery cannulation with DHCA, once the traditional approach for chronic conditions involving the aortic arch, is used by some today for acute conditions. ${ }^{5}$ In this study, we evaluated different cannulation strategies with regard to their association with adverse outcomes in patients who underwent elective proximal or total arch surgery.

\section{PATIENTS AND METHODS}

Between 2006 and 2016, 5 different cannulation sites were used in 938 patients to establish cardiopulmonary bypass (CPB) during elective proximal arch surgery. Three arteries were cannulated with a side graft: axillary $(\mathrm{n}=515)$, innominate $(\mathrm{n}=376)$, and right common carotid $(\mathrm{n}=15)$. The other 2 were cannulated directly: the aorta $(n=19)$ and the femoral artery $(n=13)$. The use of any additional cannulation site (eg, the side arm of the ascending aortic graft after replacement of the ascending aorta) during the rewarming period was not counted.

Hospital records, operative reports, and operative diagrams were retrieved from a prospectively maintained database. Informed consent was obtained for data collection whenever possible; Baylor College of Medicine's institutional review board, which approved the study, waived the consent requirement for patients who could not provide consent because of illness and whose family members were not available. Follow-up data were actively obtained through clinic visits, telephone calls to the patient or the patient's family, and communication with the patient's primary care doctor or cardiologist.

Patient characteristics were examined for a subcohort comprising the axillary and innominate cannulation groups (891 patients) and for the patients included in a propensity score analysis for axillary and innominate cannulation (564 patients, 282 pairs) (Table 1). In addition, patient characteristics were examined for the entire cohort of 938 patients (Table E1). Composite adverse event was defined as operative mortality, persistent (ie, at hospital discharge or at time of operative death) neurologic event (stroke or spinal cord injury), or persistent renal failure (need for hemodialysis). Outcome variables and intraoperative times have been previously defined.

\section{Operative Techniques}

All 938 proximal aortic procedures were elective; these consisted of 696 proximal arch replacements $(74.2 \%)$ and 242 total arch replacements $(25.8 \%)$ with ACP (Table E1). No procedure involved retrograde cerebral perfusion or DHCA. In the early part of the study period, bilateral ACP was more commonly used for the complex cases that were expected to require a prolonged ( $>30$ minutes) total ACP time. Over the years, our practice has changed. Recently, our default strategy has been to use bilateral ACP regardless of the total ACP time or the complexity of the procedure. The targeted nasopharyngeal temperature was approximately $20^{\circ} \mathrm{C}$ to $25^{\circ} \mathrm{C}$ during the period of low flow $(10-15 \mathrm{~mL} / \mathrm{kg} / \mathrm{min})$. Transesophageal echocardiography and near-infrared spectroscopy were used by the

TABLE 1. Preoperative characteristics of the axillary/innominate subcohort, overall and propensity-matched

\begin{tabular}{|c|c|c|c|c|c|c|c|}
\hline \multirow[b]{2}{*}{ Characteristics } & \multicolumn{4}{|c|}{ Overall } & \multicolumn{3}{|c|}{ Propensity-matched cohort } \\
\hline & $\begin{array}{c}\text { Overall } \\
(n=891)\end{array}$ & $\begin{array}{c}\text { Axillary } \\
(\mathrm{n}=\mathbf{5 1 5})\end{array}$ & $\begin{array}{c}\text { Innominate } \\
(\mathrm{n}=376)\end{array}$ & $\begin{array}{c}P \\
\text { value }\end{array}$ & $\begin{array}{c}\text { Axillary } \\
(\mathbf{n}=\mathbf{2 8 2})\end{array}$ & $\begin{array}{c}\text { Innominate } \\
(n=282)\end{array}$ & $\begin{array}{c}\text { Std mean } \\
\text { diff }\end{array}$ \\
\hline Age, y & $60.5 \pm 13.8$ & $61.3 \pm 13.6$ & $59.5 \pm 14.1$ & .036 & $61.1 \pm 13.5$ & $61.2 \pm 13.6$ & 0.6 \\
\hline Male & $611(68.6)$ & $352(68.3)$ & $259(68.9)$ & .923 & $195(69.1)$ & $187(66.3)$ & 6.1 \\
\hline Confirmed or suspected genetic disease & $94(10.5)$ & $49(9.5)$ & $45(12.0)$ & .286 & $17(6.0)$ & $17(6.0)$ & 0.0 \\
\hline Aortic aneurysm without dissection & $707(79.3)$ & $368(71.5)$ & $339(90.2)$ & $<.001$ & $240(85.1)$ & $241(85.5)$ & 0.9 \\
\hline Aortic dissection & $184(20.7)$ & $147(28.5)$ & $37(9.8)$ & $<.001$ & $42(14.9)$ & $41(14.5)$ & 0.9 \\
\hline Hypertension & $765(85.9)$ & $439(85.2)$ & $326(86.7)$ & .603 & $242(85.8)$ & $240(85.1)$ & 2.0 \\
\hline Diabetes & 77 (8.6) & $40(7.8)$ & $37(9.8)$ & .333 & $21(7.4)$ & $22(7.8)$ & 1.3 \\
\hline Tobacco use, current or past & $505(56.7)$ & $304(59.0)$ & $201(53.5)$ & .112 & $159(56.4)$ & $160(56.7)$ & 0.7 \\
\hline NYHA class III or IV & $215(24.1)$ & $155(30.1)$ & $60(16.0)$ & $<.001$ & $49(17.4)$ & $58(20.6)$ & 7.7 \\
\hline Cardiac history* & $214(24.0)$ & $119(23.1)$ & $95(25.3)$ & .506 & $64(22.7)$ & $64(22.7)$ & 0.0 \\
\hline Pulmonary history $\dagger$ & $214(24.0)$ & $119(23.1)$ & $95(25.3)$ & .506 & $53(18.8)$ & $61(21.6)$ & 7.0 \\
\hline Renal history $\ddagger$ & $214(24.0)$ & $119(23.1)$ & $95(25.3)$ & .506 & $4(1.4)$ & $5(1.8)$ & 2.8 \\
\hline Cerebrovascular history $\S$ & $111(12.5)$ & $75(14.6)$ & $36(9.6)$ & .034 & $32(11.3)$ & $33(11.7)$ & 1.1 \\
\hline Previous proximal aortic repair|| & $176(19.8)$ & $145(28.2)$ & $31(8.2)$ & $<.001$ & $38(13.5)$ & $30(10.6)$ & 7.6 \\
\hline Redo sternotomy & $268(30.1)$ & $214(41.6)$ & $54(14.4)$ & $<.001$ & $63(22.3)$ & $53(18.8)$ & 8.3 \\
\hline
\end{tabular}

Data are presented as mean \pm standard deviation for continuous variables and $\mathrm{n}(\%)$ for categorical variables. NYHA, New York Heart Association. *History of angina, myocardial infarction, coronary artery bypass grafting, percutaneous transluminal coronary angiography/stenting, or arrhythmia/heart block. $\dagger$ History of asthma or chronic obstructive

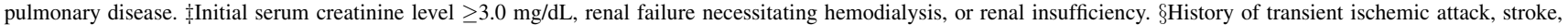
carotid endarterectomy, or cerebral aneurysm. \|Previous ascending aortic repair or aortic root replacement. 


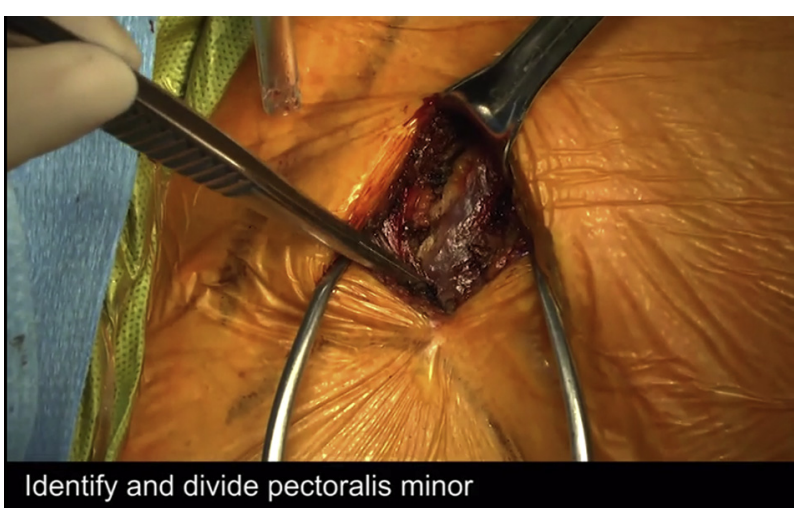

VIDEO 1. Axillary and innominate cannulation strategies. Video available at: http://www.jtcvsonline.org/article/S0022-5223(17)32893-3/fulltext.

anesthesia team. For blood pressure monitoring, we preferred to use the right radial arterial line, but quite often, the anesthesia team placed right and left radial arterial lines so that they could monitor the patient's blood pressure during cannulation. In redo cases, an additional femoral arterial line was used to monitor the blood pressure.

The timeline for our cannulation strategy was as follows: Early in the 10-year study period, for CPB, we cannulated the axillary artery with a side graft; however, in the last 6 to 7 years, we started using the innominate artery with a side graft, which became our preferred site on the basis of the results of our early experience (Video 1 ). ${ }^{6}$ We have previously described our rationale for preferring innominate over axillary cannulation. ${ }^{3,6}$ The common carotid artery was cannulated in patients whose innominate artery was short or aneurysmal. All 3 of these arteries were cannulated with an $8-\mathrm{mm}$ side graft (10-mm for obese patients). Femoral artery cannulation was our default strategy for elective redo proximal aortic procedures when severe venous or aortic bleeding was encountered on sternal entry. In this series, the femoral artery was always cannulated directly, not through a side graft. Direct aortic cannulation was used in elective cases when malperfusion or inadequate flow was detected immediately after CPB was established. Our decision-making process is shown in Figure 1. Our proximal arch and total arch techniques have been previously described. ${ }^{3,7}$ In all cases, a preoperative computed tomography scan was performed. Epiaortic ultrasound of the proximal thoracic aorta was not routinely used, but it was occasionally used in cases of malperfusion.

\section{Statistical Analysis}

Both a multivariable analysis and a propensity score-matching analysis were performed. For the propensity score-matching analysis, we estimated the propensity score by using a multivariate logistic regression model. We included the following preoperative covariates in the model: patient age, sex, confirmed or suspected genetic disease, hypertension, diabetes, tobacco use (current or past), New York Heart Association class III or IV, cardiac history, pulmonary history, renal history, cerebrovascular

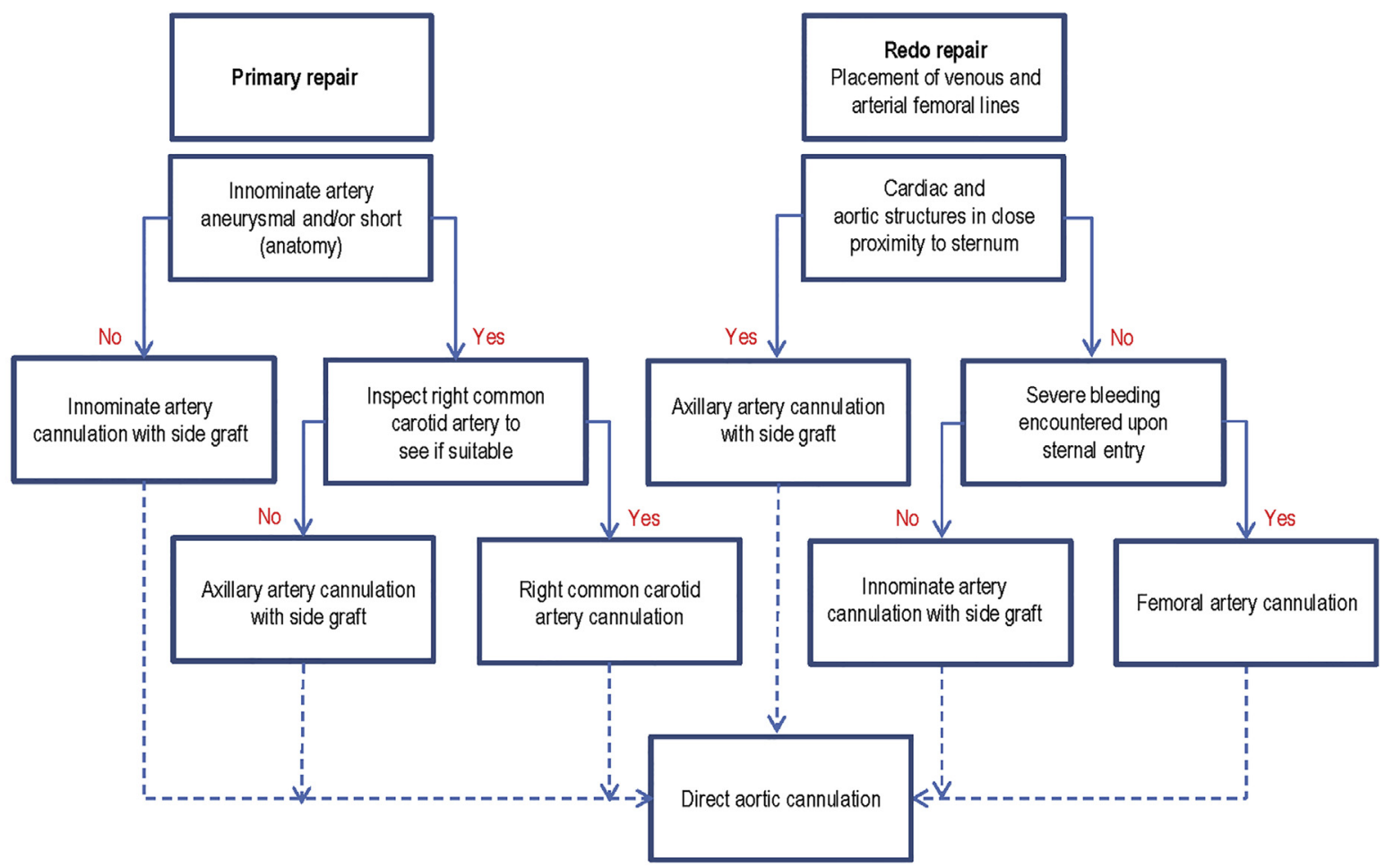

Inadequate flow

or malperfusion detected

immediately after

$\mathrm{CPB}$ was initiated

FIGURE 1. Diagram showing the decision-making process for arterial cannulation in elective aortic arch repair. $C P B$, Cardiopulmonary bypass. 
TABLE 2. Short-term complications of the axillary/innominate subcohort, overall and propensity-matched

\begin{tabular}{|c|c|c|c|c|c|c|c|}
\hline \multirow[b]{2}{*}{ Characteristics } & \multicolumn{4}{|c|}{ Overall } & \multicolumn{3}{|c|}{ Propensity-matched cohort } \\
\hline & $\begin{array}{c}\text { Overall } \\
(n=891)\end{array}$ & $\begin{array}{c}\text { Axillary } \\
(n=515)\end{array}$ & $\begin{array}{c}\text { Innominate } \\
(\mathbf{n}=\mathbf{3 7 6})\end{array}$ & $\begin{array}{c}P \\
\text { value }\end{array}$ & $\begin{array}{c}\text { Axillary } \\
(n=282)\end{array}$ & $\begin{array}{c}\text { Innominate } \\
(\mathrm{n}=\mathbf{2 8 2})\end{array}$ & $\begin{array}{c}P \\
\text { value }\end{array}$ \\
\hline Operative death* & $58(6.5)$ & $37(7.2)$ & $21(5.6)$ & .413 & $12(4.3)$ & $21(7.4)$ & .150 \\
\hline Stroke, persistent & $25(2.8)$ & $18(3.5)$ & $7(1.9)$ & .21 & $8(2.8)$ & $6(2.1)$ & .791 \\
\hline Overall stroke $\dagger$ & $34(3.8)$ & $25(4.9)$ & $9(2.4)$ & .086 & $13(4.6)$ & $8(2.8)$ & .383 \\
\hline Composite adverse event $t$ & $81(9.1)$ & $55(10.7)$ & $26(6.9)$ & .07 & $21(7.4)$ & $25(8.9)$ & .627 \\
\hline Renal dysfunction/insufficiency & $65(7.3)$ & $43(8.3)$ & $22(5.9)$ & .198 & $16(5.7)$ & $22(7.8)$ & .405 \\
\hline \multicolumn{8}{|c|}{ Renal failure necessitating hemodialysis } \\
\hline Transient & $14(1.6)$ & $9(1.7)$ & $5(1.3)$ & .824 & $1(0.4)$ & $5(1.8)$ & .219 \\
\hline Permanent & $31(3.5)$ & $21(4.1)$ & $10(2.7)$ & .339 & $9(3.2)$ & $10(3.5)$ & .99 \\
\hline Respiratory failure & $200(22.4)$ & $143(27.8)$ & $57(15.2)$ & $<.001$ & $71(25.2)$ & $52(18.4)$ & .067 \\
\hline Tracheostomy & $72(8.1)$ & $53(10.3)$ & $19(5.1)$ & .007 & $24(8.5)$ & $19(6.7)$ & .780 \\
\hline Heart block requiring pacemaker & $61(6.8)$ & $38(7.4)$ & $23(6.1)$ & .547 & $17(6.0)$ & $16(5.7)$ & .99 \\
\hline Bleeding requiring operation & $27(3.0)$ & $20(3.9)$ & $7(1.9)$ & .123 & $8(2.8)$ & $6(2.1)$ & .791 \\
\hline
\end{tabular}

Data are presented as n (\%). *Intraoperative, 30-day, or in-hospital death. †Persistent or transient stroke. $\ddagger$ Operative death, persistent stroke, persistent renal failure necessitating hemodialysis, or persistent paraparesis/paraplegia.

history, previous proximal aortic repair, redo sternotomy, and aortic pathology.

A 1-to-1 matching without replacement by propensity score was performed by using the nearest neighbor method with a caliper of 0.05 standard deviation of the logit. Matching was carried out with the psmatch2 package in STATA (version 14; STATA, College Station, Tex; Computing Resource Center, Santa Monica, Calif). Balance in the baseline covariates of matched data was examined by using standardized differences. We compared the postoperative variables of the axillary artery group and innominate artery group by using the McNemar test. The standardized mean differences were reported. The overall survival rates of both groups were compared with the stratified log-rank test. The association between cannulation site and overall survival was evaluated with a Cox proportional hazards regression model stratified by matched pairs. The assumption of proportional hazards was examined with scaled Schoenfeld residuals.

For the multivariable analysis, we built a multivariable logistic regression model with the following postoperative variables: operative death, persistent stroke, overall stroke, renal dysfunction, bleeding requiring reoperation, respiratory failure, and composite adverse event. We first compared the outcomes of the innominate and the axillary groups by using univariate analyses and then entered the clinically relevant and statistically significant preoperative and intraoperative variables into the model and applied a backward selection method to choose the final multivariable models with the smallest Akaike information criterion.

For the models of our entire cohort $(\mathrm{n}=938)$ and our axillary/ innominate subcohort $(\mathrm{n}=891)$, the following variables were considered for model entry: cannulation site, aortic pathology, age, tobacco use (current or past), New York Heart Association class III or IV, cardiac history, pulmonary history, renal history, cerebrovascular history, redo sternotomy, CPB time, full arch procedure, concomitant aortic root repair or replacement, concomitant coronary artery bypass grafting, cardiac ischemic time, ACP time $>30$ minutes, and year of operation.

\section{RESULTS}

\section{Operative Mortality}

In our analysis of the subcohort comprising the 891 patients in the axillary and innominate groups, the 2 groups showed no difference in operative death $(7.2 \%$ vs $5.6 \%, P=.413$ ) (Table 2). Similar results were found in the propensity-matched analysis (282 pairs), where the 2 groups showed no difference in operative death (axillary vs innominate, $4.3 \%[\mathrm{n}=12]$ vs $7.4 \%$ $[\mathrm{n}=21] ; P=.150)$. When we then excluded the patients with neurologic events (overall stroke) from the operative mortality category, the propensity-matched patients continued to show no difference in operative mortality.

In our analysis of the entire cohort, operative mortality was found to be $7.0 \%(n=66)$ overall, $7.2 \%(n=37)$ for the axillary cannulation group, and $5.6 \%(\mathrm{n}=21)$ for the innominate cannulation group (Table E2). Mortality was greatest among the patients who underwent femoral artery cannulation $(30.8 \% ; n=4)$.

In the multivariable analysis of the axillary/innominate subcohort (Table 3), neither axillary nor innominate artery cannulation was significantly associated with operative death. The same results were found for the entire cohort (Table E3). Predictors of operative mortality for the axillary/innominate subcohort were prolonged CPB time (odds ratio [OR], 1.015; 95\% confidence interval [CI], $1.01-1.02 ; P<.001)$, preoperative pulmonary history (OR, 2.564; 95\% CI, 1.343-4.853; $P=.004$ ), patient age (OR, 1.103; 95\% CI, 1.068-1.143; $P<.001$ ), full arch procedure (OR, 3.794; 95\% CI, 1.991-7.31, $P<.001$ ), and New York Heart Association class III or IV (OR, $2.811 ; 95 \%$ CI, 1.504-5.265, $P=.001$ ) (Table 3). The predictors of mortality for the entire cohort were similar, with a few small differences (prolonged ACP time was a predictor instead of the full arch procedure) (Table E3). 
TABLE 3. Multivariable regression analysis of the axillary/innominate subcohort

\begin{tabular}{|c|c|c|c|c|}
\hline Outcome variable & $P$ value & Odds ratio & \multicolumn{2}{|c|}{ 95 $\%$ Confidence interval } \\
\hline \multicolumn{5}{|l|}{ Operative death } \\
\hline Full arch & $<.001$ & 3.794 & 1.991 & 7.310 \\
\hline NYHA class III or IV & .001 & 2.811 & 1.504 & 5.265 \\
\hline Pulmonary history & .004 & 2.564 & 1.343 & 4.853 \\
\hline Age, y & $<.001$ & 1.103 & 1.068 & 1.143 \\
\hline CPB time, $\min$ & $<.001$ & 1.015 & 1.01 & 1.02 \\
\hline \multicolumn{5}{|l|}{$\mathrm{C}$ index 0.877} \\
\hline \multicolumn{5}{|l|}{ Stroke, persistent } \\
\hline Renal history & .006 & 7.498 & 1.497 & 29.308 \\
\hline Cerebrovascular history & .002 & 3.374 & 1.522 & 7.130 \\
\hline ACP time $>30 \mathrm{~min}$ & .003 & 3.842 & 1.648 & 9.690 \\
\hline \multicolumn{5}{|l|}{ C index 0.793} \\
\hline \multicolumn{5}{|l|}{ Overall stroke } \\
\hline Renal history & .017 & 5.738 & 1.146 & 21.585 \\
\hline Cerebrovascular history & .002 & 3.374 & 1.522 & 7.130 \\
\hline ACP time $>30 \mathrm{~min}$ & .031 & 2.182 & 1.073 & 4.494 \\
\hline \multicolumn{5}{|l|}{$\mathrm{C}$ index 0.709} \\
\hline \multicolumn{5}{|l|}{ HL test $P$ value 1.0} \\
\hline \multicolumn{5}{|c|}{ Renal failure necessitating hemodialysis, persistent } \\
\hline CPB time, $\min$ & $<.001$ & 1.016 & 1.009 & 1.024 \\
\hline \multicolumn{5}{|l|}{$\mathrm{C}$ index 0.797} \\
\hline \multicolumn{5}{|l|}{ HL test $P$ value .5} \\
\hline \multicolumn{5}{|l|}{ Bleeding requiring operation } \\
\hline No variables found to be sig & & & & \\
\hline \multicolumn{5}{|l|}{$\mathrm{C}$ index 0.64} \\
\hline \multicolumn{5}{|l|}{ HL test $P$ value 1.0} \\
\hline \multicolumn{5}{|l|}{ Respiratory failure } \\
\hline Full arch & $<.001$ & 2.198 & 1.467 & 3.290 \\
\hline Tobacco use, current or past & .008 & 1.637 & 1.143 & 2.362 \\
\hline Aortic dissection & .028 & 1.595 & 1.049 & 2.414 \\
\hline $\mathrm{CPB}$ time, $\min$ & $<.001$ & 1.01 & 1.006 & 1.013 \\
\hline Year of operation & .004 & 0.919 & 0.867 & 0.974 \\
\hline \multicolumn{5}{|l|}{$\mathrm{C}$ index 0.759} \\
\hline \multicolumn{5}{|l|}{ HL test $P$ value .5} \\
\hline \multicolumn{5}{|l|}{ Composite adverse event } \\
\hline Renal history & .022 & 4.439 & 1.212 & 16.009 \\
\hline ACP time $>30 \mathrm{~min}$ & .035 & 2.246 & 1.047 & 4.725 \\
\hline NYHA class III or IV & .006 & 2.121 & 1.236 & 3.615 \\
\hline Cerebrovascular history & .018 & 2.106 & 1.116 & 3.867 \\
\hline Pulmonary history & .020 & 1.934 & 1.101 & 3.351 \\
\hline Age, y & $<.001$ & 1.068 & 1.042 & 1.097 \\
\hline $\mathrm{CPB}$ time, $\min$ & $<.001$ & 1.01 & 1.006 & 1.015 \\
\hline \multicolumn{5}{|l|}{$\mathrm{C}$ index 0.848} \\
\hline HL test $P$ value 1.0 & & & & \\
\hline
\end{tabular}

NYHA, New York Heart Association; $C P B$, cardiopulmonary bypass; $H L$, Hosmer-Lemeshow; $A C P$, antegrade cerebral perfusion.

\section{Neurologic Outcomes}

Of the 938 patients in the entire cohort, $27(2.9 \%)$ suffered persistent stroke (Table E2). The majority $(n=25)$ of the persistent strokes were embolic (17 axillary,
6 innominate, 1 femoral/left-side distribution, 1 direct aortic/left-side distribution), and 2 were hemorrhagic (1 axillary, 1 innominate). Femoral cannulation was associated with overall stoke $(P=.023)$ in the multivariable 
analysis of the entire cohort of patients, but the femoral cannulation group was too small to draw conclusions from (Table E3).

Of the 891 patients in the axillary/innominate subcohort, $25(2.8 \%)$ suffered persistent stroke; these included 18 $(3.5 \%)$ of the patients in the axillary cannulation group and $7(1.9 \%)$ of the patients in the innominate cannulation group (Table 2). Of the 23 embolic strokes that occurred, 7 had a right-side-only distribution (axillary $=6$, innominate $=1$ ), 10 had a left-side-only distribution (axillary $=7$, innominate $=3$ ), and 6 had a bilateral distribution (axillary $=4$, innominate $=2$ ).

In the multivariable analysis of the subcohort comprising the 2 main cannulation strategies (axillary and innominate), neither axillary nor innominate cannulation independently predicted stroke (Table 3). Similarly, in the analysis of the propensity-matched patients, the 2 groups showed no significant difference in overall stroke rate, with the axillary cannulation group having only a slightly greater rate than the innominate cannulation group $(4.6 \%[\mathrm{n}=13]$ vs $2.8 \%$ [n $=8], P=.383$ ) (Table 2).

Independent predictors of persistent stroke for both the entire cohort $(\mathrm{n}=938$ patients $)$ and the axillary/innominate subcohort $(\mathrm{n}=891$ patients) were previous history of cerebrovascular disease, previous renal history, and ACP time $>30$ minutes (Table E3 and Table 3).

\section{Local Injury}

The cannulated vessel was not directly injured in any case. No patient who underwent right axillary cannulation had permanent brachial plexus injury.

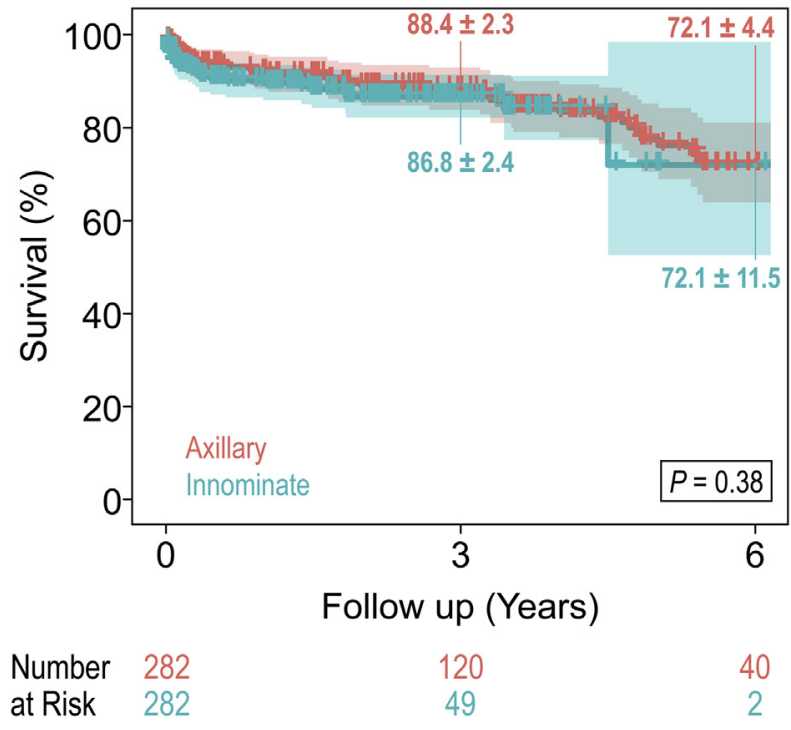

FIGURE 2. Kaplan-Meier survival curves for propensity-matched patients who underwent axillary or innominate artery cannulation.

\section{Follow-up}

The median follow-up period was 2.3 [interquartile range, 1.1-4.0] years (range, 30 days to 11.2 years) for the surviving patients with 30 -day follow-up data available ( $\mathrm{n}=728$ for the overall group). Kaplan-Meier curves showed no difference in long-term survival between the matched axillary and innominate cannulation groups (Figure 2): Survival rates were $92.1 \%$ (standard error [SE], 0.019; CI, 0.875-0.950) for the axillary group versus $89.7 \%$ (SE, 0.019; CI, 0.852-0.929) for the innominate group at 1 year and $72.1 \%$ (SE, 0.044; CI, 0.6325-0.797) versus $72.1 \%$ (SE, 0.115; CI, 0.427-0.882) at 6 years $(P=.378)$.

\section{DISCUSSION}

Unilateral or bilateral ACP, in conjunction with hypothermic circulatory arrest, is used in aortic surgery to safely extend the period of circulatory arrest and facilitate complex arch procedures. ${ }^{8-14}$ To facilitate ACP delivery, different cannulation strategies have been implemented. ${ }^{1,3-6,15-21}$ In this study, we evaluated our experience with various cannulation strategies in patients who underwent elective proximal and total arch surgery during the past decade.

The mortality rates associated with using the 2 most common cannulation sites - the axillary and innominate arteries - did not differ significantly in the analysis of the entire cohort or in that of the smaller subcohort comprising only the axillary and innominate cannulation patients. The same results were confirmed in the analysis of the propensity-matched subgroups $(P=.150)$. The mortality rate observed in our femoral cannulation group was probably high because of that group's small size and because the femoral artery was our emergent bailout cannulation site during redo sternotomy when bleeding was encountered on sternal entry (Figure 1). It is also possible that the bleeding upon sternal entry could have caused these patients to become hypotensive, which could have contributed to the greater incidence of stroke seen in the group that underwent femoral cannulation. An embolic event due to retrograde flow to the cerebral circulation with femoral arterial inflow is possible as well. Our mortality rates of $7.0 \%$ and $7.2 \%$ for the entire cohort and the axillary cannulation group, respectively, are close to the $8.4 \%$ rate $(7.0 \%$ for axillary cannulation via a side graft, $7.8 \%$ for direct axillary cannulation) reported by Svensson and colleagues ${ }^{20}$ and the $4.6 \%$ rate reported by Etz and colleagues. ${ }^{17}$ Both of these studies included emergency and elective cases, and both associated femoral cannulation with greater mortality than the use of other cannulation sites, as in our study. Other groups have reported outstanding results with femoral artery cannulation. ${ }^{22}$ The group from Emory reported a greater operative mortality 
rate $(10.7 \%)$ in 122 elective cases, probably because they all were total arch procedures. ${ }^{23}$ This group uses right axillary artery cannulation with an 8 - $\mathrm{mm}$ side graft.

Axillary and innominate artery cannulation were not independently associated with overall or persistent stroke in either multivariable analysis, and the propensitymatching analysis confirmed these results. Although the 2 groups showed similar rates of persistent stroke in our propensity-matching analysis $(P=.791)$, the rate was slightly greater in the axillary group. In contrast, Chu and colleagues ${ }^{16}$ from Canada found that neurologic events were more frequent in their innominate cannulation group (66 patients) than in their axillary cannulation group (74 patients), but the difference was not statistically significant. In that review of 140 patients who underwent a hemiarch procedure, the reported stroke rates for the innominate cannulation and axillary cannulation groups were $3.0 \%$ and $1.4 \%$, respectively. It should be noted that in that study, the innominate artery was cannulated directly and the axillary artery was cannulated via a side graft.

We noticed a greater stroke rate in our axillary cannulation group, but our cohort included patients who underwent total arch operations, and approximately one third underwent redo procedures. Most strokes that occur during aortic arch repair are embolic, and specific characteristics of the patient's aortic disease, such as having a heavily atheromatous aortic arch, may mediate the association between stroke rate and specific cannulation strategies. For this reason, we avoid cannulating the innominate artery if we believe that it is involved with heavy atheroma.

In addition, our propensity-matching analysis showed that the patients in the axillary group had more respiratory complications than those in the innominate group $(P=.067)$, which agrees with the results of others. ${ }^{16}$ In our multivariable analysis of the axillary/innominate subcohort, cannulation site was not found to be an independent predictor of respiratory failure. Although it was not assessed in this study, our experience suggests that patients undergoing complicated procedures with a prolonged $\mathrm{CPB}$ time suffer more coagulopathy, receive more products, and end up on a ventilator more often.

Regarding the technical aspects of cannulation, different groups have compared the results of direct axillary or innominate cannulation versus using a side graft. ${ }^{4,6,16,20}$ Although some have associated direct axillary cannulation with stroke, ${ }^{20}$ others have reported excellent results. ${ }^{4}$ In our practice, we use an 8- or 10-mm Gelweave side graft (Vascutek Ltd, Renfrewshire, Scotland, United Kingdom) and apply a partial occluding clamp to the vessel because we find it easier. We avoid blindly placing wires or using sequential dilators in the innominate artery, because this increases stroke risk even if the intended arterial inflow cannula is small. For a heavily atherosclerotic arch with excessive atheroma, we prefer to use the right axillary artery (Figure 1).

\section{Study Limitations}

The comparisons made in this study were inherently limited by the differences in surgical year, despite the various statistical analyses performed (multivariable and propensity-matching). Also, our study was limited by its retrospective design and the inherent biases thereof. Our surgical technique underwent modifications during the study period; the recent trend has been to use innominate artery cannulation and bilateral ACP for most procedures (regardless of complexity), but there was not a specific cutoff date for this change.

Furthermore, although the 2 main groups (axillary and innominate cannulation) were large, our group sizes for the other cannulation sites were relatively small. To show the various cannulation strategies available while also providing an in-depth analysis of the 2 most common strategies, we performed 2 multivariable analyses: 1 for the entire cohort and 1 for a smaller subcohort that included only the axillary and innominate cannulation patients. In addition, we do not know exactly how many patients experienced temporary tingling in the right arm due to axillary surgical dissection, but this always resolved after a few days.

\section{CONCLUSIONS}

Different cannulation strategies can be used to establish arterial inflow for elective proximal and total arch cases. Our multivariable analysis confirmed the results of our propensity-matching analysis, which led us to believe that innominate and right axillary cannulation in elective arch surgery provide similar neuroprotection and are interchangeable, depending on the circumstances. The other cannulation strategies, although less popular, are useful in selected cases in which the innominate and right axillary sites cannot be used.

\section{Conflict of Interest Statement}

Dr Preventza consults for Medtronic, Inc, and W. L. Gore \& Associates. Previously, she has received travel expenses from both Cook, Inc, and Gore. Dr Coselli consults for, receives royalties and a departmental educational grant from, and participates in clinical trials for Vascutek Terumo. Dr LeMaire participates in clinical trials for Medtronic, Inc, W. L. Gore \& Associates, and Vascutek Terumo. All other authors have nothing to disclose with regard to commercial support.

Stephen N. Palmer, PhD, ELS, and Heather Leibrecht, MS, ELS, assisted in editing the manuscript. 


\section{References}

1. Ayyash B, Tranquilli M, Elefteriades JA. Femoral artery cannulation for thoracic aortic surgery: safe under transesophageal echocardiographic control. J Thorac Cardiovasc Surg. 2011;142:1478-81.

2. Gulbins H, Pritisanac A, Ennker J. Axillary versus femoral cannulation for aortic surgery: enough evidence for a general recommendation? Ann Thorac Surg. 2007;83:1219-24.

3. Preventza O, Garcia A, Tuluca A, Henry M, Cooley DA, Simpson K, et al. Innominate artery cannulation for proximal aortic surgery: outcomes and neurological events in 263 patients. Eur J Cardiothorac Surg. 2015;48:937-42; discussion 42.

4. Strauch JT, Spielvogel D, Lauten A, Lansman SL, McMurtry K, Bodian CA, et al. Axillary artery cannulation: routine use in ascending aorta and aortic arch replacement. Ann Thorac Surg. 2004;78:103-8; discussion 8.

5. De Paulis R, Czerny M, Weltert L, Bavaria J, Borger MA, Carrel TP, et al. Current trends in cannulation and neuroprotection during surgery of the aortic arch in Europe. Eur J Cardiothorac Surg. 2015;47:917-23.

6. Preventza O, Bakaeen FG, Stephens EH, Trocciola SM, de la Cruz KI, Coselli JS. Innominate artery cannulation: an alternative to femoral or axillary cannulation for arterial inflow in proximal aortic surgery. J Thorac Cardiovasc Surg. 2013; 145:S191-6.

7. Preventza O, Garcia A, Cooley DA, Haywood-Watson RJ, Simpson K, Bakaeen FG, et al. Total aortic arch replacement: a comparative study of zone 0 hybrid arch exclusion versus traditional open repair. J Thorac Cardiovasc Surg. 2015;150:1591-8; discussion 1598-600.

8. Angeloni E, Benedetto U, Takkenberg JJ, Stigliano I, Roscitano A, Melina G, et al. Unilateral versus bilateral antegrade cerebral protection during circulatory arrest in aortic surgery: a meta-analysis of 5100 patients. J Thorac Cardiovasc Surg. 2014;147:60-7.

9. Leshnower BG. Invited commentary. Ann Thorac Surg. 2015;99:2031.

10. Mezrow CK, Sadeghi AM, Gandsas A, Shiang HH, Levy D, Green R, et al. Cerebral blood flow and metabolism in hypothermic circulatory arrest. Ann Thorac Surg. 1992:54:609-15; discussion 615-6.

11. Okita Y, Miyata H, Motomura N, Takamoto S. A study of brain protection during total arch replacement comparing antegrade cerebral perfusion versus hypothermic circulatory arrest, with or without retrograde cerebral perfusion: analysis based on the Japan Adult Cardiovascular Surgery Database. J Thorac Cardiovasc Surg. 2015;149:S65-73.

12. Strauch JT, Spielvogel D, Haldenwang PL, Zhang N, Weisz D, Bodian CA, et al Impact of hypothermic selective cerebral perfusion compared with hypothermic cardiopulmonary bypass on cerebral hemodynamics and metabolism. Eur J Cardiothorac Surg. 2003;24:807-16.
13. Tian DH, Wan B, Bannon PG, Misfeld M, LeMaire SA, Kazui T, et al. A meta-analysis of deep hypothermic circulatory arrest alone versus with adjunctive selective antegrade cerebral perfusion. Ann Cardiothorac Surg. 2013;2:261-70

14. Zierer A, Risteski P, El-Sayed Ahmad A, Moritz A, Diegeler A, Urbanski PP. The impact of unilateral versus bilateral antegrade cerebral perfusion on surgical outcomes after aortic arch replacement: a propensity-matched analysis. J Thorac Cardiovasc Surg. 2014;147:1212-7; discussion 1217-8.

15. Banbury MK, Cosgrove DM III. Arterial cannulation of the innominate artery. Ann Thorac Surg. 2000;69:957.

16. Chu MW, Losenno KL, Gelinas JJ, Garg V, Dickson J, Harrington A, et al. Innominate and axillary cannulation in aortic arch surgery provide similar neuroprotection. Can J Cardiol. 2016;32:117-23.

17. Etz CD, Plestis KA, Kari FA, Silovitz D, Bodian CA, Spielvogel D, et al. Axillary cannulation significantly improves survival and neurologic outcome after atherosclerotic aneurysm repair of the aortic root and ascending aorta. Ann Thorac Surg. 2008;86:441-6; discussion 446-7.

18. Huang FJ, Wu Q, Ren CW, Lai YQ, Yang S, Rui QJ, et al. Cannulation of the innominate artery with a side graft in arch surgery. Ann Thorac Surg. 2010;89:800-3.

19. Jassar AS, Vallabhajosyula P, Bavaria JE, Gutsche J, Desai ND, Williams ML, et al. Direct innominate artery cannulation: an alternate technique for antegrade cerebral perfusion during aortic hemiarch reconstruction. J Thorac Cardiovasc Surg. 2016;151:1073-8.

20. Svensson LG, Blackstone EH, Rajeswaran J, Sabik JF III, Lytle BW, Gonzalez-Stawinski G, et al. Does the arterial cannulation site for circulatory arrest influence stroke risk? Ann Thorac Surg. 2004;78: 1274-84; discussion 84.

21. Svensson LG, Nadolny EM, Kimmel WA. Multimodal protocol influence on stroke and neurocognitive deficit prevention after ascending/arch aortic operations. Ann Thorac Surg. 2002;74:2040-6.

22. Tsiouris A, Elkinany S, Ziganshin BA, Elefteriades JA. Open Seldinger-guided femoral artery cannulation technique for thoracic aortic surgery. Ann Thorac Surg. 2016;101:2231-5.

23. Leshnower BG, Kilgo PD, Chen EP. Total arch replacement using moderate hypothermic circulatory arrest and unilateral selective antegrade cerebral perfusion. J Thorac Cardiovasc Surg. 2014;147:1488-92.

Key Words: axillary artery cannulation, innominate artery cannulation, arch surgery, cannulation, neurologic outcomes, circulatory arrest 
TABLE E1. Preoperative characteristics, demographics, and intraoperative details of the entire cohort

\begin{tabular}{|c|c|c|c|c|c|c|c|}
\hline Characteristics & $\begin{array}{c}\text { Overall } \\
(\mathbf{n}=938)\end{array}$ & $\begin{array}{l}\text { Axillary } \\
(\mathbf{n}=\mathbf{5 1 5})\end{array}$ & $\begin{array}{c}\text { Innominate } \\
(\mathbf{n}=\mathbf{3 7 6})\end{array}$ & $\begin{array}{l}\text { Direct aortic } \\
\quad(\mathbf{n}=19)\end{array}$ & $\begin{array}{l}\text { Carotid } \\
(\mathbf{n}=15)\end{array}$ & $\begin{array}{l}\text { Femoral } \\
(\mathrm{n}=13)\end{array}$ & $\begin{array}{c}P \\
\text { value }\end{array}$ \\
\hline Age, $y$ & $60.6 \pm 13.7$ & $61.3 \pm 13.6$ & $59.5 \pm 14.0$ & $62.4 \pm 9.1$ & $63.9 \pm 8.2$ & $59.8 \pm 16.3$ & .268 \\
\hline Male & $644(68.7)$ & $352(68.4)$ & $259(68.9)$ & $14(73.7)$ & $12(80.0)$ & $7(53.9)$ & .649 \\
\hline Confirmed or suspected genetic disease & $99(10.6)$ & $49(9.5)$ & $45(12.0)$ & $1(5.3)$ & $2(13.3)$ & $2(15.4)$ & .584 \\
\hline Aortic aneurysm without dissection & 707 (75.4) & $346(67.2)$ & $334(88.8)$ & $16(84.2)$ & $8(53.3)$ & $3(23.1)$ & $<.001$ \\
\hline Aortic dissection & $231(24.6)$ & $169(32.8)$ & $42(11.1)$ & $3(5.3)$ & $7(46.7)$ & $10(76.9)$ & $<.001$ \\
\hline Hypertension & $806(85.9)$ & $439(85.2)$ & $326(86.7)$ & $18(94.7)$ & $14(93.3)$ & $9(69.2)$ & .314 \\
\hline Diabetes & $80(8.5)$ & $40(7.8)$ & $37(9.8)$ & $2(10.5)$ & $1(6.7)$ & $0(0)$ & .684 \\
\hline Tobacco use, current or past & $531(56.6)$ & $304(59.0)$ & $201(53.5)$ & $10(52.6)$ & $10(66.7)$ & $6(46.2)$ & .397 \\
\hline NYHA class III or IV & $231(24.6)$ & $155(30.1)$ & $60(16.0)$ & $7(36.8)$ & $2(13.3)$ & $7(53.9)$ & $<.001$ \\
\hline Cardiac history* & $230(24.5)$ & $119(23.1)$ & $95(25.3)$ & $2(10.5)$ & $7(46.7)$ & $7(53.9)$ & .016 \\
\hline Pulmonary history $\dagger$ & 199 (21.2) & $119(23.1)$ & $67(17.8)$ & $7(36.8)$ & $3(20.0)$ & $3(23.1)$ & .142 \\
\hline Renal history $y_{\dagger}^{\dagger}$ & $15(1.6)$ & $8(1.6)$ & $6(1.6)$ & $0(0)$ & $0(0)$ & $1(7.7)$ & .457 \\
\hline Cerebrovascular history $\S$ & $116(12.4)$ & 75 (14.6) & $36(9.6)$ & $0(0)$ & $4(26.7)$ & $1(7.7)$ & .024 \\
\hline Previous proximal aortic repair $\mid$ & $191(20.4)$ & $145(28.2)$ & $31(8.2)$ & $1(5.3)$ & $5(33.3)$ & $9(69.2)$ & $<.001$ \\
\hline Redo sternotomy & $286(30.5)$ & 214 (41.6) & $54(14.4)$ & $2(10.5)$ & $6(40.0)$ & $10(76.9)$ & $<.001$ \\
\hline CPB time, $\min$ & $144.7 \pm 55.9$ & $146.5 \pm 55.9$ & $138.1 \pm 49.7$ & $166.2 \pm 95.8$ & $162.3 \pm 74.4$ & $209.6 \pm 77.8$ & .002 \\
\hline ACP time $>30 \mathrm{~min}$ & $330(35.2)$ & $218(42.3)$ & $82(21.8)$ & $6(31.6)$ & $14(93.3)$ & $10(76.9)$ & $<.001$ \\
\hline Cardiac ischemic time, min & $97.4 \pm 39.6$ & $93.1 \pm 39.9$ & $102.5 \pm 38.0$ & $93.7 \pm 44.5$ & $115.3 \pm 46.2$ & $100.4 \pm 40.0$ & .001 \\
\hline ACP time, $\min$ & $33.8 \pm 25.6$ & $37.4 \pm 27.6$ & $27.5 \pm 20.0$ & $26.4 \pm 23.2$ & $65.5 \pm 28.8$ & $49.2 \pm 26.9$ & $<.001$ \\
\hline $\mathrm{ACP}$, unilateral & $319(34.0)$ & $271(52.6)$ & $26(6.9)$ & $14(73.7)$ & $3(20.0)$ & $5(38.5)$ & $<.001$ \\
\hline ACP, bilateral & $619(66.0)$ & $244(47.4)$ & $350(93.1)$ & $5(26.3)$ & $12(80.0)$ & $8(61.5)$ & $<.001$ \\
\hline Full arch & $242(25.8)$ & $168(32.6)$ & $52(13.8)$ & $7(36.8)$ & $11(73.3)$ & $4(30.8)$ & $<.001$ \\
\hline Hemiarch & $696(74.2)$ & $347(67.4)$ & $324(86.2)$ & $12(63.2)$ & $4(26.7)$ & $9(69.2)$ & $<.001$ \\
\hline $\begin{array}{l}\text { Concomitant aortic root repair } \\
\text { or replacement }\end{array}$ & $303(32.3)$ & $118(22.9)$ & $176(46.8)$ & $6(31.6)$ & $2(13.3)$ & $1(7.7)$ & $<.001$ \\
\hline Concomitant aortic valve replacement\# & $266(28.4)$ & $147(28.5)$ & $107(28.5)$ & $6(31.6)$ & $3(20.0)$ & $3(23.1)$ & .938 \\
\hline Concomitant $\mathrm{CABG}^{* *}$ & $152(16.2)$ & $90(17.5)$ & $58(15.4)$ & $1(5.3)$ & $2(13.3)$ & $1(7.7)$ & .641 \\
\hline
\end{tabular}

Data are presented as mean \pm standard deviation for continuous variables and $\mathrm{n}(\%)$ for categorical variables. $N Y H A$, New York Heart Association; $C P B$, cardiopulmonary bypass; $A C P$, antegrade cerebral perfusion; $C A B G$, coronary artery bypass grafting. *History of angina, myocardial infarction, CABG, percutaneous transluminal coronary angiography/stenting, or arrhythmia/heart block. †History of asthma or chronic obstructive pulmonary disease. $\ddagger$ Initial serum creatinine level $\geq 3.0 \mathrm{mg} / \mathrm{dL}$, renal failure necessitating hemodialysis, or renal insufficiency. §History of transient ischemic attack, stroke, carotid endarterectomy, or cerebral aneurysm. $\|$ Previous ascending aortic repair or aortic root replacement. $\lceil$ Aortic valve-sparing; composite valve graft, tissue or mechanical; homograft; or stentless tissue. \#Tissue or mechanical. **1, 2, 3, or 4 vessels. 
TABLE E2. Short-term complications of the entire cohort

\begin{tabular}{|c|c|c|c|c|c|c|c|}
\hline Complication & $\begin{array}{c}\text { Overall } \\
(\mathbf{n}=938)\end{array}$ & $\begin{array}{c}\text { Axillary } \\
(\mathbf{n}=\mathbf{5 1 5})\end{array}$ & $\begin{array}{c}\text { Innominate } \\
(\mathbf{n}=376)\end{array}$ & $\begin{array}{l}\text { Direct aortic } \\
\quad(n=19)\end{array}$ & $\begin{array}{l}\text { Carotid } \\
(\mathbf{n}=15)\end{array}$ & $\begin{array}{l}\text { Femoral } \\
(\mathbf{n}=13)\end{array}$ & $\begin{array}{c}P \\
\text { value }\end{array}$ \\
\hline Operative death* & $66(7.0)$ & $37(7.2)$ & $21(5.6)$ & $2(10.5)$ & $2(13.3)$ & $4(30.8)$ & .008 \\
\hline Stroke, persistent & $27(2.9)$ & $18(3.5)$ & $7(1.9)$ & $1(5.3)$ & $0(0)$ & $1(7.7)$ & .233 \\
\hline Overall stroke $\dagger$ & $38(4.1)$ & $25(4.9)$ & $9(2.4)$ & $1(5.3)$ & $0(0)$ & $3(23.1)$ & .014 \\
\hline Composite adverse event $\ddagger$ & $92(9.8)$ & $55(10.7)$ & $26(6.9)$ & $3(15.8)$ & $4(26.7)$ & $4(30.8)$ & .003 \\
\hline Renal dysfunction/insufficiency & $75(8.0)$ & $43(8.4)$ & $22(5.9)$ & $3(15.8)$ & $0(0)$ & $7(53.9)$ & $<.001$ \\
\hline \multicolumn{8}{|c|}{ Renal failure necessitating hemodialysis } \\
\hline Transient & $15(1.6)$ & $9(1.8)$ & $5(1.3)$ & $1(5.3)$ & $0(0)$ & $0(0)$ & .560 \\
\hline Permanent & $34(3.6)$ & $21(4.1)$ & $10(2.7)$ & $1(5.3)$ & $1(6.7)$ & $1(7.7)$ & .277 \\
\hline Respiratory failure & $224(23.9)$ & $143(27.8)$ & $57(15.2)$ & $8(42.1)$ & $6(40.0)$ & $10(76.9)$ & $<.001$ \\
\hline Tracheostomy & $79(8.4)$ & $53(10.3)$ & $19(5.1)$ & $3(15.8)$ & $2(13.3)$ & $2(15.4)$ & .010 \\
\hline Heart block requiring pacemaker & $66(7.1)$ & $38(7.4)$ & $23(6.1)$ & $3(15.8)$ & $1(6.7)$ & $1(7.7)$ & .397 \\
\hline Bleeding requiring operation & $30(3.2)$ & $20(3.9)$ & $7(1.9)$ & $0(0)$ & $0(0)$ & $3(23.1)$ & .013 \\
\hline
\end{tabular}

Data are presented as n (\%). *Intraoperative, 30-day, or in-hospital death. †Persistent or transient stroke. †Operative death, persistent stroke, persistent renal failure necessitating hemodialysis, or persistent paraparesis/paraplegia. 
TABLE E3. Multivariable regression analysis of the entire cohort

\begin{tabular}{|c|c|c|c|c|}
\hline \multirow{2}{*}{$\begin{array}{l}\text { Outcome variable } \\
\text { Operative death }\end{array}$} & \multirow{2}{*}{$P$ value } & \multirow{2}{*}{ Odds ratio } & \multicolumn{2}{|c|}{ 95 $\%$ Confidence interval } \\
\hline & & & & \\
\hline ACP time $>30 \mathrm{~min}$ & $<.001$ & 2.960 & 1.595 & 5.631 \\
\hline Pulmonary history & .001 & 2.609 & 1.439 & 4.703 \\
\hline NYHA class III and IV & .018 & 2.004 & 1.12 & 3.556 \\
\hline Age, y & $<.001$ & 1.092 & 1.06 & 1.128 \\
\hline $\mathrm{CPB}$ time, $\min$ & $<.001$ & 1.013 & 1.009 & 1.018 \\
\hline \multicolumn{5}{|l|}{$\begin{array}{l}\mathrm{C} \text { index } 0.858 \\
\mathrm{HL} \text { test } P \text { value } .2\end{array}$} \\
\hline \multicolumn{5}{|l|}{ Stroke, persistent } \\
\hline Renal history & .004 & 8.088 & 1.613 & 30.928 \\
\hline Cerebrovascular history & $<.001$ & 4.563 & 1.962 & 10.246 \\
\hline ACP time $>30 \mathrm{~min}$ & .004 & 3.335 & 1.489 & 7.976 \\
\hline \multicolumn{5}{|l|}{$\begin{array}{l}\mathrm{C} \text { index } 0.753 \\
\mathrm{HL} \text { test } P \text { value } 1.0\end{array}$} \\
\hline \multicolumn{5}{|l|}{ Overall stroke } \\
\hline Femoral & .023 & 5.343 & 1.063 & 20.732 \\
\hline Renal history & .003 & 7.671 & 1.826 & 27.151 \\
\hline Cerebrovascular history & .001 & 3.645 & 1.673 & 7.623 \\
\hline \multicolumn{5}{|l|}{$\begin{array}{l}\mathrm{C} \text { index } 0.683 \\
\mathrm{HL} \text { test } P \text { value } .7\end{array}$} \\
\hline \multicolumn{5}{|c|}{ Renal failure necessitating dialysis, persistent } \\
\hline NYHA class III and IV & .003 & 3.196 & 1.502 & 6.905 \\
\hline Pulmonary history & .015 & 2.661 & 1.193 & 5.852 \\
\hline Full arch & .044 & 2.241 & 1.016 & 4.939 \\
\hline Age, y & $<.001$ & 1.098 & 1.055 & 1.147 \\
\hline $\mathrm{CPB}$ time, $\min$ & $<.001$ & 1.011 & 1.006 & 1.017 \\
\hline \multicolumn{5}{|l|}{$\begin{array}{l}\mathrm{C} \text { index } 0.877 \\
\text { HL test } P \text { value } .8\end{array}$} \\
\hline \multicolumn{4}{|l|}{ Bleeding requiring operation } & \\
\hline Femoral & .009 & 6.473 & 1.334 & 24.299 \\
\hline \multicolumn{5}{|l|}{$\mathrm{C}$ index 0.685} \\
\hline \multicolumn{5}{|l|}{ Respiratory failure } \\
\hline \multicolumn{5}{|l|}{ Cannulation site (ref. axillary) } \\
\hline Femoral & .007 & 7.174 & 1.872 & 36.14 \\
\hline Full arch & $<.001$ & 2.119 & 1.458 & 3.08 \\
\hline Tobacco use, current or past & .01 & 1.586 & 1.122 & 2.26 \\
\hline Redo sternotomy & .037 & 1.515 & 1.024 & 2.23 \\
\hline Age, y & $<.001$ & 1.033 & 1.018 & 1.05 \\
\hline CPB time, $\min$ & $<.001$ & 1.009 & 1.006 & 1.01 \\
\hline $\begin{array}{l}\mathrm{C} \text { index } 0.768 \\
\mathrm{HL} \text { test } P \text { value } .4\end{array}$ & & & & \\
\hline
\end{tabular}


TABLE E3. Continued

\begin{tabular}{lccc}
\hline \multicolumn{1}{c}{ Outcome variable } & $\boldsymbol{P}$ value & Odds ratio & 95\% Confidence interval \\
\hline Composite adverse event & & & 1.648 \\
ACP time $>30$ min & $<.001$ & 2.883 & 1.133 \\
Cerebrovascular history & .015 & 2.059 & 1.115 \\
Pulmonary history & .016 & 1.890 & 1.10 .1 \\
NYHA class III and IV & .018 & 1.827 & 1.045 \\
Aortic dissection & .033 & 1.783 & 1.035 \\
Age, y & $<.001$ & 1.059 & 1.007 \\
CPB time, min & $<.001$ & 1.011 & 0.282 \\
Composite root replacement & .131 & 0.582 & 3.652 \\
C index 0.837 & & & 1.063 \\
HL test $P$ value 1.0 & & & 1.086 \\
\hline
\end{tabular}

$\overline{A C P}$, Antegrade cerebral perfusion; NYHA, New York Heart Association; $C P B$, cardiopulmonary bypass; $H L$, Hosmer-Lemeshow. 